\title{
Carbon Market Sensitive Green Supply Chain Network Design
}

\section{Amin Chaabane, jr. eng., Ph.D. Student}

\author{
Supervised by
}

\section{Prof. Amar Ramudhin and Prof. Marc Paquet}

Department of Automated Manufacturing Engineering École de Technologie Supérieure

Montreal, Quebec, Canada 


\section{Outline}

- Introduction

- Context

- Motivation and objective

- Kyoto protocol

- Carbon Market

- Literature

- Limitations

- Model formulation

- Experimentation

- Managerial insights

- Conclusion 


\section{Introduction - Context}

- Supply chain strategies of last decade :

- Warehouse consolidation

- Lean and agile supply chains

- Just in time

- Offshore manufacturing

- Low cost country sourcing

- How green are these strategies?

- How relevant are they if the carbon trading market became a reality (a price tag for carbon emissions)? 


\section{Introduction - Context}

\section{Climate Change : who is the responsible !!!}

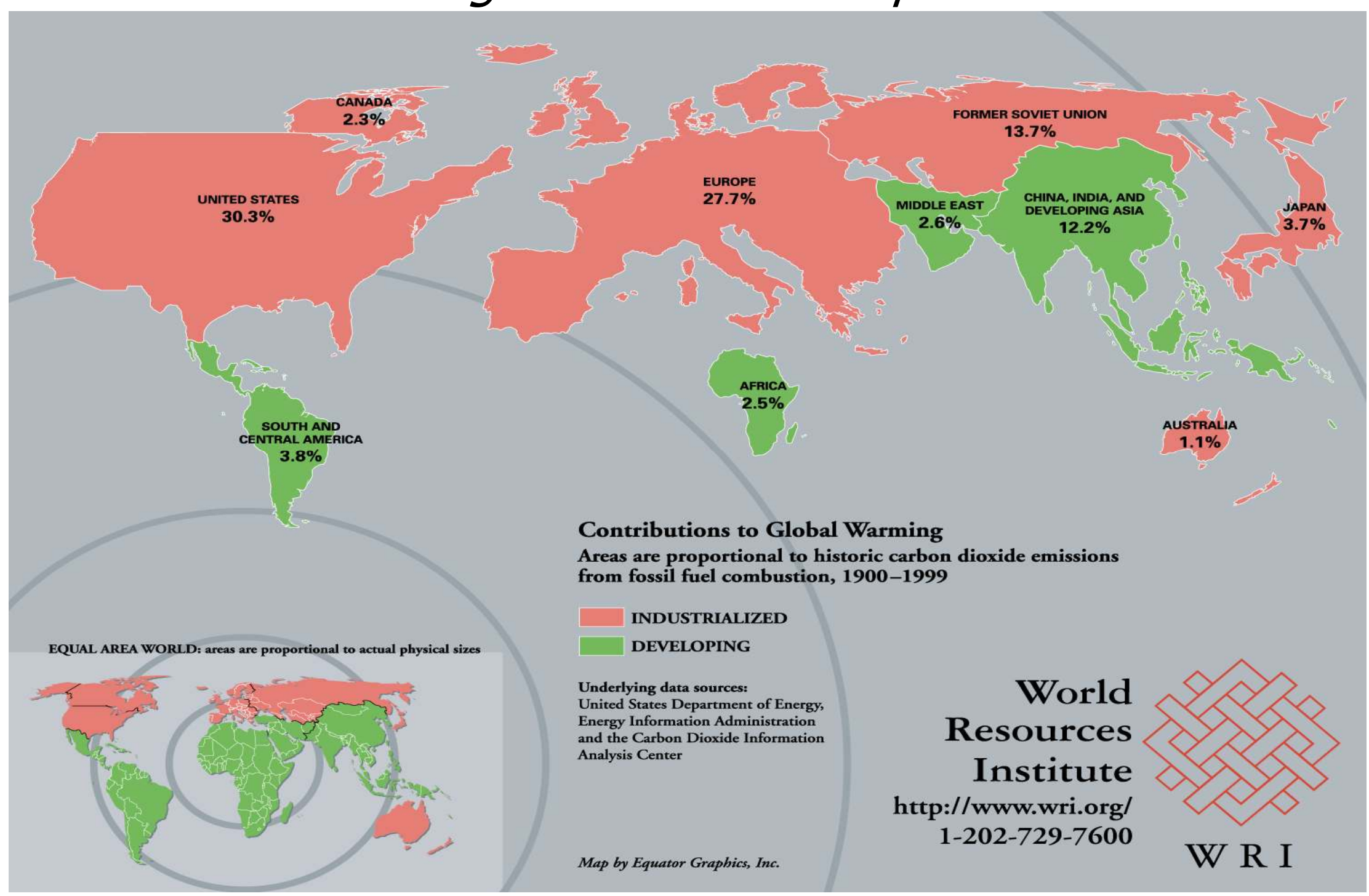

(C) 2008 A. Chaabane, A. Ramudhin, M. Paquet 


\section{Introduction - Context}

Aggregate Contributions of Major GHG Emitting Countries

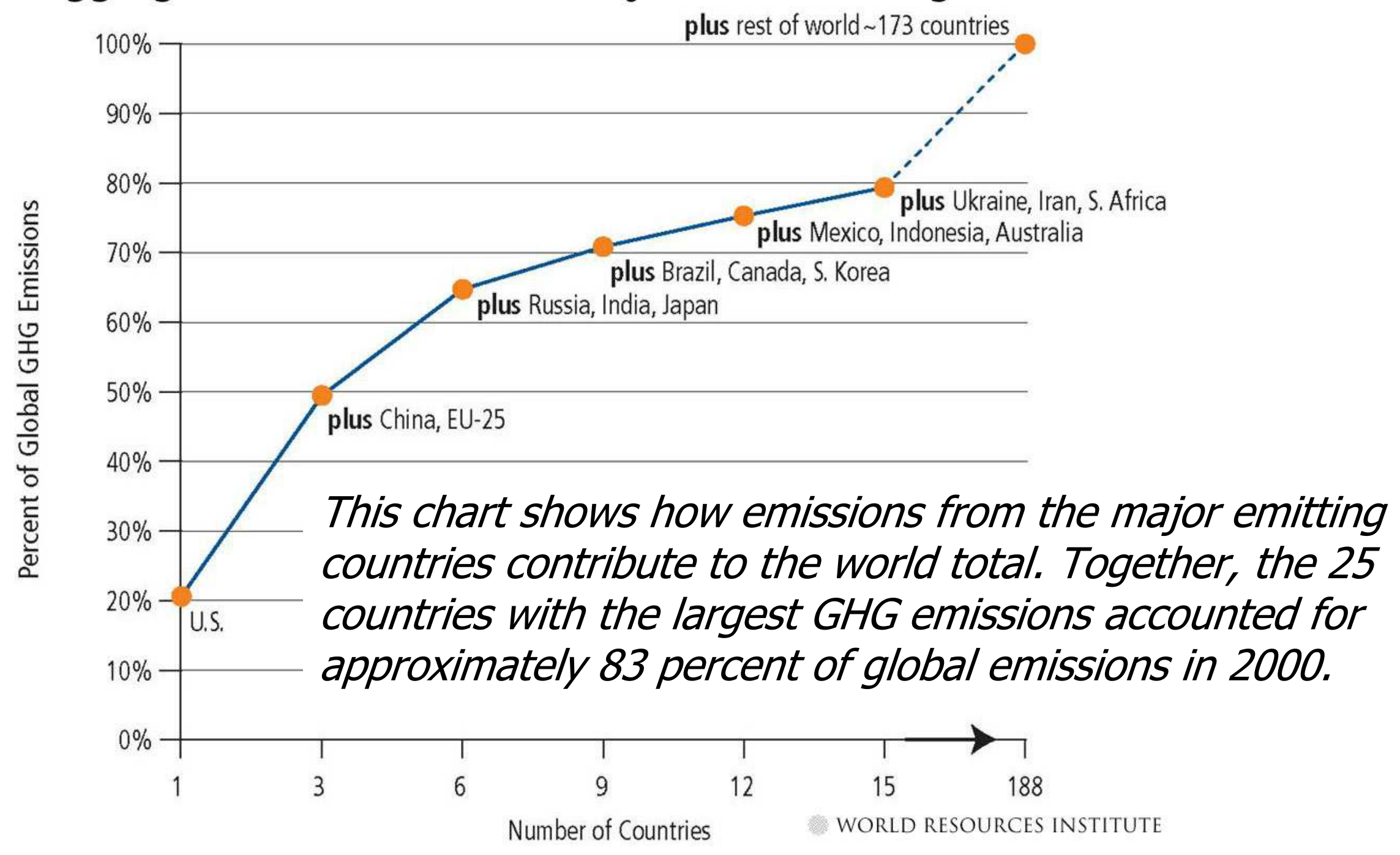

(C) 2008 A. Chaabane, A. Ramudhin, M. Paquet 
The Kyoto Protocol: key features

- Entry into force: February 16, 2005

- US and Australia did not ratify

- Differentiated commitments:

- Developed countries and countries with economies in transition agree to quantified legally-binding targets (overall objective leads to a $5 \%$ reduction from 1990 levels by 2008-2012)

- Six gases,:

- carbon dioxide (CO2),

- methane $(\mathrm{CH} 4)$,

- nitrous oxide (N2O),

- Sulphur hexafluoride (SF6),

- Per fluorocarbons (PFC) and

- Hydro fluorocarbons (HFC). 
The Kyoto Protocol: key features

- Target should be achieved through:

- Domestic Reductions

- Carbon Sinks: direct human-induced land use change and forestry activities

- International Credits (Kyoto Mechanisms):

- International Emissions Trading

- Project -Based: Joint Implementation (in industrialized countries)

- Project - Based: Clean Development Mechanism (in developing countries)

- Negotiations on next period (post-2012) to start in 2005 


\section{Introduction - Context}

\section{- Carbon trading markets: a new reality for Green Supply Chain Management}
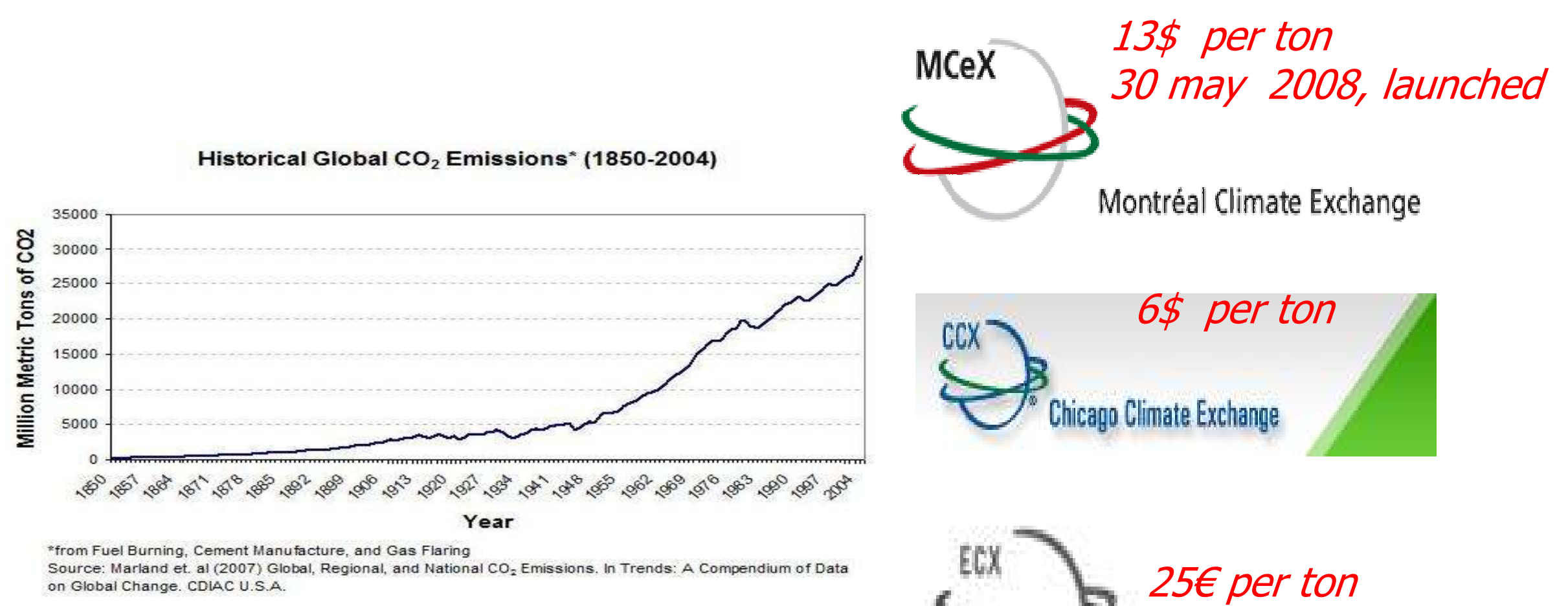

on Global Change. CDIAC U.S.A.

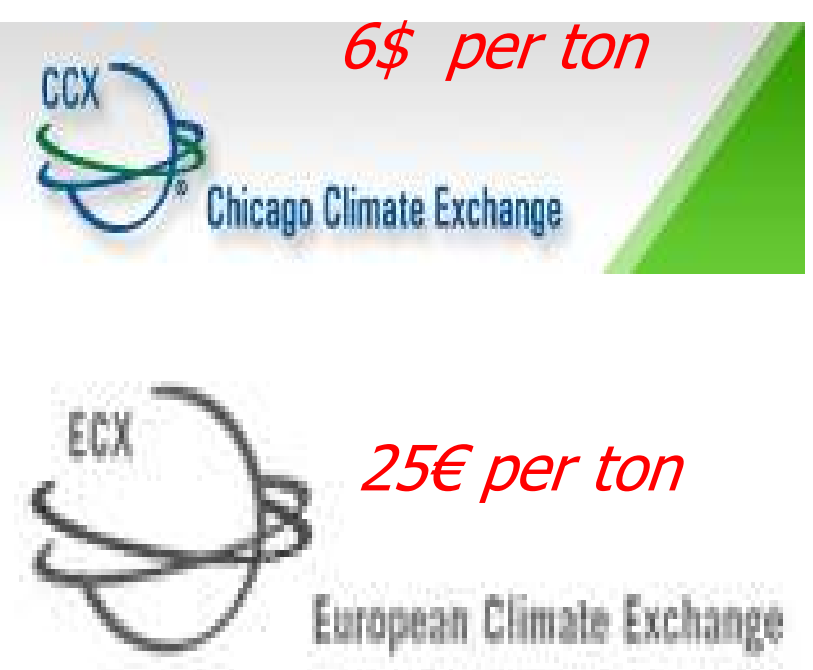

(C) 2008 A. Chaabane, A. Ramudhin, M. Paquet 
Project-Based Transactions

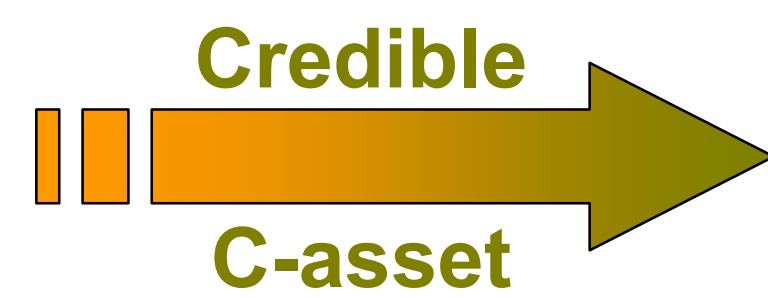

\section{Allowance Markets}

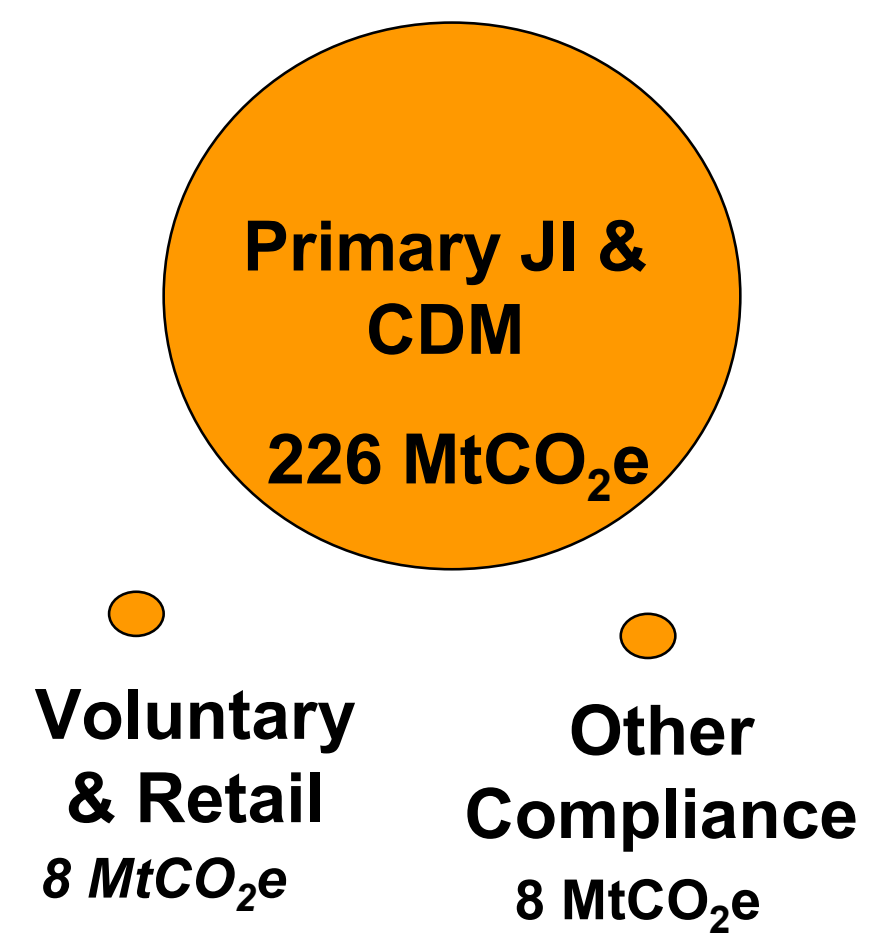

(C) 2008 A. Chaabane, A. Ramudhin, M. Paquet

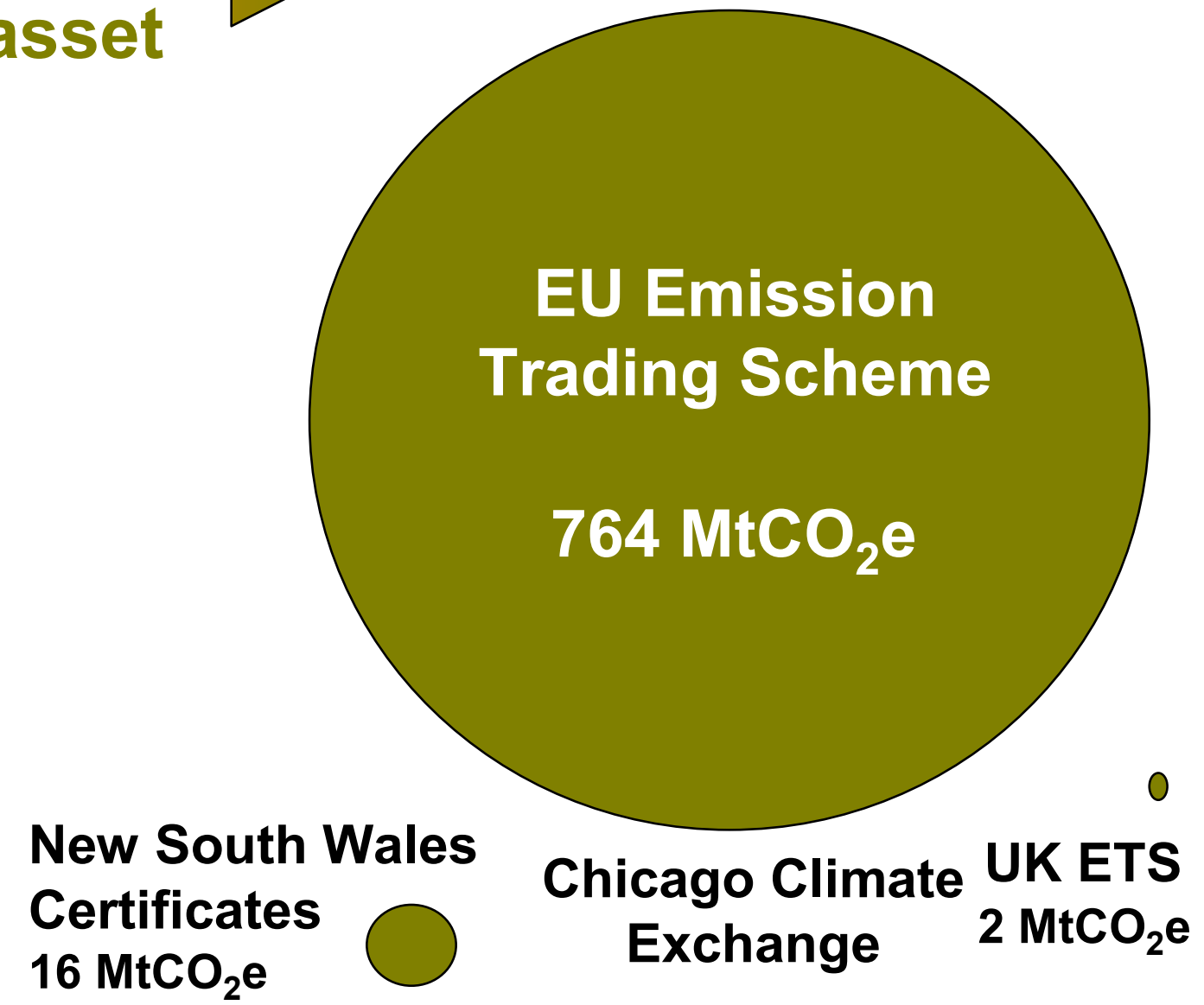

$8 \mathrm{MtCO}_{2} \mathrm{e}$ 


\section{Introduction - Context}

- Trends :

- 'Corporate Responsibility' reporting (green accounts) is on the rise (from $45 \%$ of Global fortune 250 companies in 2002 to $67 \%$ in 2005) ${ }^{[1]}$

- Texas Instruments saved USD 8 million each year by reducing its transit packaging budget for its semiconductor business through source reduction, recycling, and use of reusable packaging systems

[1] Source : KPMG "International Survey of Corporate Responsibility reporting in 2005"

- Regulations:

- The government of Canada (ecoAction, 2007) plans to regulate both GHG emissions and air pollutants

- "impose mandatory targets on industry to achieve a goal of an absolute reduction of 150 mega tons in GHG emissions by 2020"

- The U.S. Environmental Protection Agency's (EPA, 2006) announced that by 2012, 160 Million Metric Tons of Carbon Equivalent (MMTCE) of emission will be reduced

- "99 MMTCE will be reduced in the industry sector and 15 MMTCE will be reduced in the transportation sector" 


\section{Introduction - Objective}

- Develop a decision support system (DSS) for strategic and environmental supply chain network design analysis :

- Calculate a supply chain's existing carbon footprint (calculation of GHG emissions) based on the current supply chain network structure

- Determine the most cost effective supply chain network design based on user-defined GHG reduction targets

- Incorporate carbon offsets into cost and footprint calculations to optimize where carbon credits should be purchased and applied: Environmental Cost 
- Green supply chain management (GSCM) and problems context :

- Green design

- Environmentally conscious design (ECD)

- Life-cycle assessment/analysis (LCA)

- Green operations

- Supplier selection

- Green manufacturing and remanufacturing

- Reverse logistics and network design

- Waste management

- Minimize the use of energy

Srivastava, S.K. (2007) Green supply-chain management: A state-of-the-art literature review, International Journal of Management Reviews, 9, 1, 53-80.

(C) 2008 A. Chaabane, A. Ramudhin, M. Paquet 
- Green supply chain management (GSCM) based methodology / approach :

- Empirical studies

- Case studies

- Interviews and surveys

- Though papers

- Simulation and game theory

- Mathematical modelling

- Non Linear Programming (LP)

- Multi-criteria decision making

- LP and Mixed Integer LP

Srivastava, S.K. (2007) Green supply-chain management: A state-of-the-art literature review, International Journal of Management Reviews, 9, 1, 53-80.

(C) 2008 A. Chaabane, A. Ramudhin, M. Paquet 


\section{Literature - Limitations}

- GSCM studied supply chain problems much more form operational point of view

- For the green supply chain network design

- The problem is not studied enough

- Research stress on reverse logistics activities

- Unable to quantify clearly the real impact of such improvement relative to GHG emission reduction and the supply chain configuration

- Lack of standardized, comprehensive and up-to-date data

- Industry is struggling to find the right trade-off between

- Green supply chains

- Lean supply chains

- Agile supply chains 


\section{A GSCM framework}

\section{Environmental conscious supply chain network design}

Green supply chain management

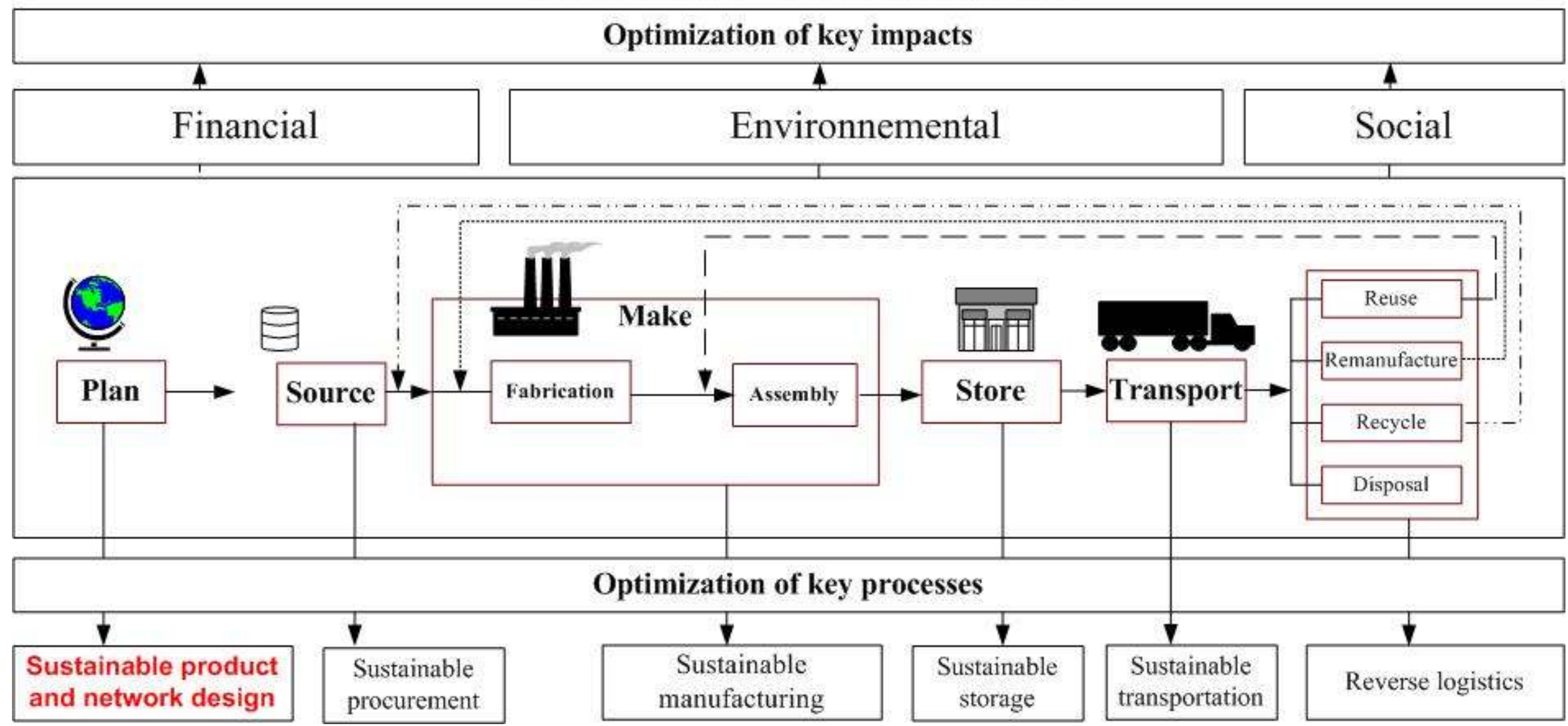

Sustainable product

Adapted from the SCOR Model

(C) 2008 A. Chaabane, A. Ramudhin, M. Paquet

http://www.supply-chain.org/cs/root/scor_tools_resources/scor_model/scor_model 


\section{Methodology: Mathematical programming}

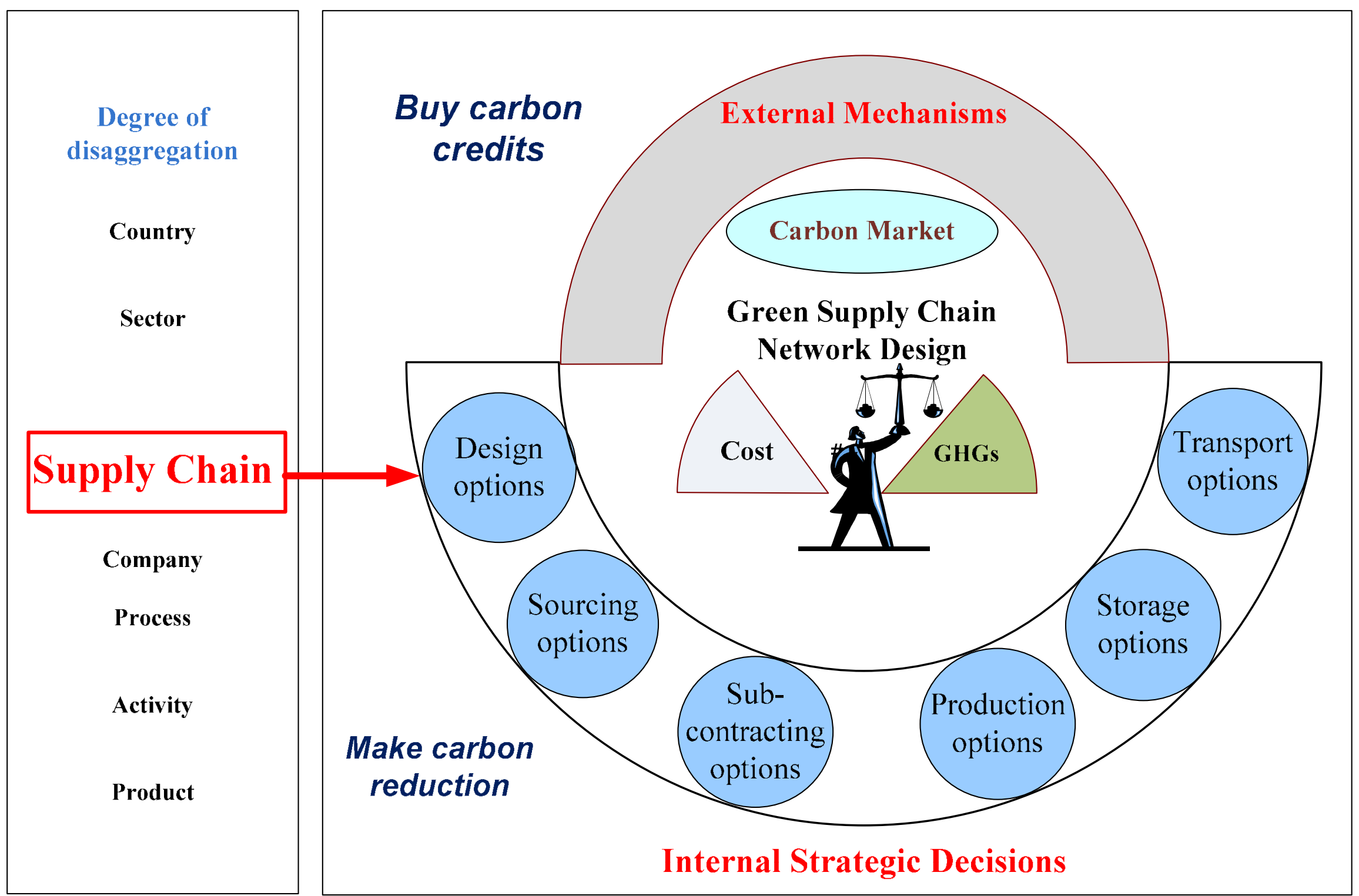

(C) 2008 A. Chaabane, A. Ramudhin, M. Paquet 


\section{Supply Chain Configuration}

- Products : Bill-Of-Materials

- Raw materials

- Sub-assemblies

- Finished products

- Supply Chain Configuration

- Potential Suppliers

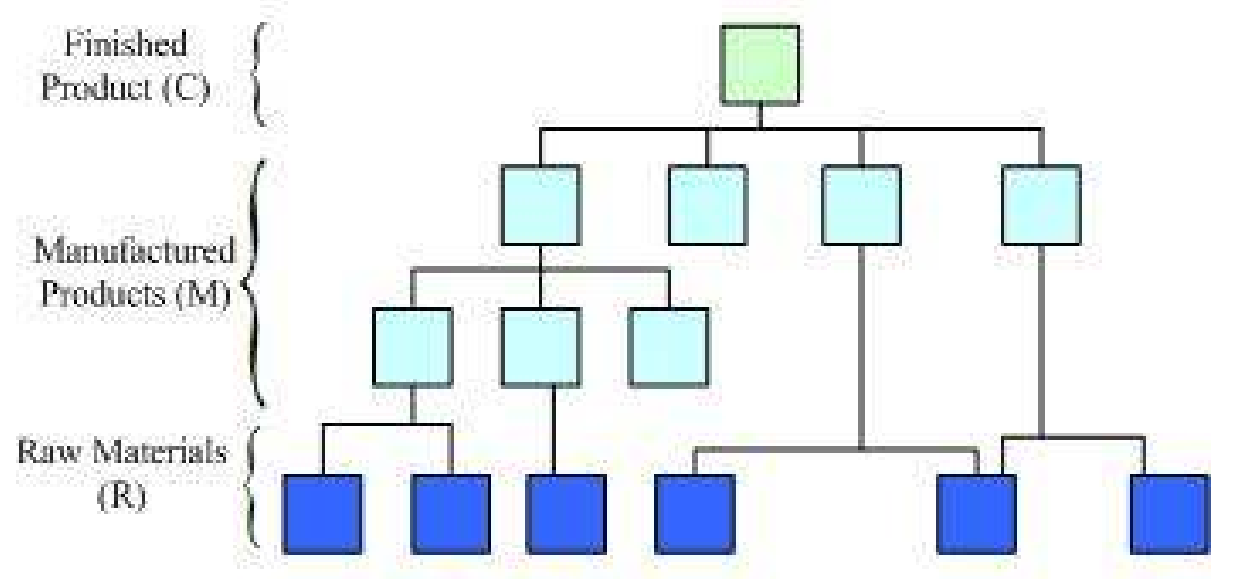

- Potential Subcontractors

- Production plants

- Transportation modes

- Road

- Rail

- Air

- GHG emission

- Carbon dioxide $\left(\mathrm{CO}_{2}\right)$

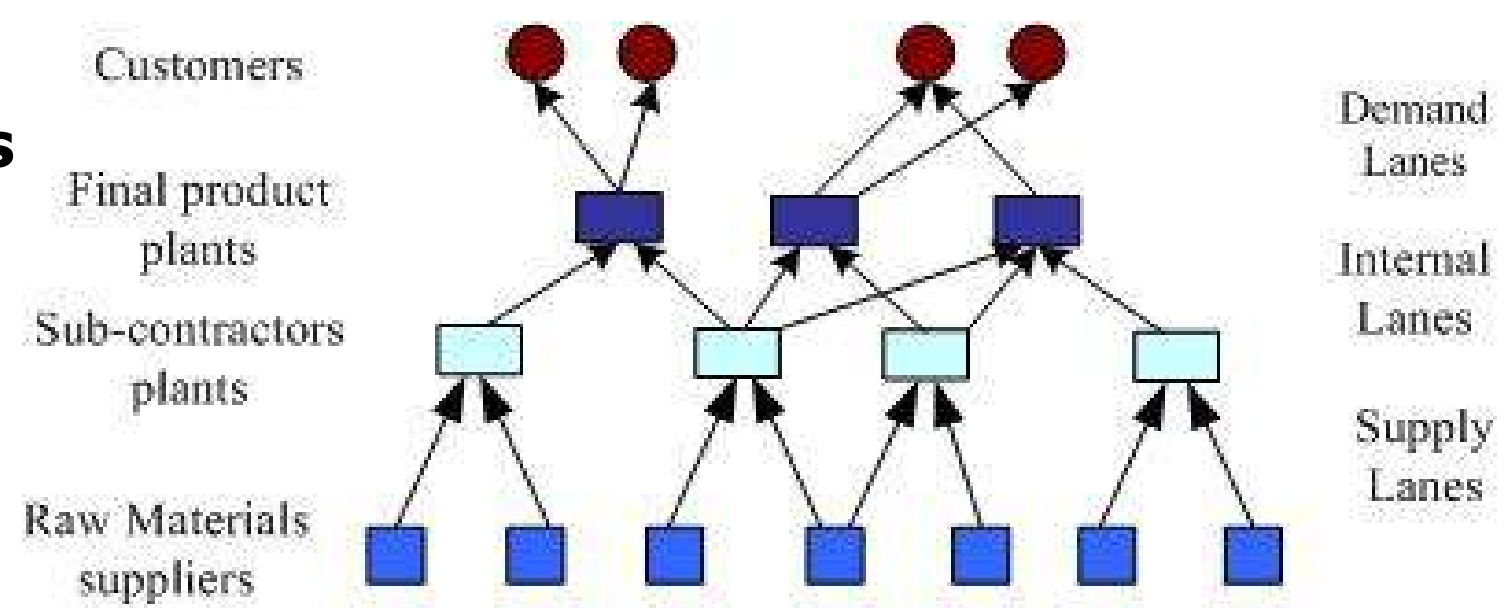




\section{Model formulation}

- Minimize the total supply chain cost

- Majors decisions are:

- Select

- Suppliers, sub-contractors and production centers

- Transportation modes to use between nodes

- Assign

- Raw materials to suppliers

- Sub-assemblies to sub-contractors

- Determine

- Products flow between nodes

- GHG emissions (carbon dioxide equivalent)

- Subject to

- Technological constraints 


\section{Formulation - Objective Function}

- The total cost includes fixed and variable costs

- Fixed costs are:

- Fixed costs for facilities (a)

- Assignment of raw materials to suppliers and manufactured products to subcontractors (b)

- Variable costs are of five types:

- Supply of raw materials and manufacturing products (c)

- Shipment costs (related to the number of shipments) (d)

- Transportation costs (e)

- GHG emissions credits ( $f$ )

$$
\begin{aligned}
\operatorname{Min} \mathbf{F}_{1}= & \underbrace{\sum_{i \in V \cup S} \lambda_{i} A_{i}}_{(a)}+\underbrace{\sum_{p \in M \cup R} \sum_{i \in S_{p} \cup V_{p}} a_{i p} Y_{i p}}_{(b)}+\underbrace{\sum_{p \in M \cup R} \sum_{i \in S_{p} \cup V_{p}} c_{i p} X_{i p}}_{(b)} \\
& +\underbrace{\sum_{i \in S \cup V} \sum_{j \in S \cup D} \sum_{i \in K} l_{i}^{k} U_{i j}^{k}}_{(c)}+\underbrace{\sum_{p \in M \cup R} \sum_{i \in S_{p} \cup \cup_{p}} \sum_{j \in S(S \cup C(P)) \cup D} \sum_{k \in K} t_{i j p}^{k} F_{i j p}^{k}}_{(e)}
\end{aligned}
$$

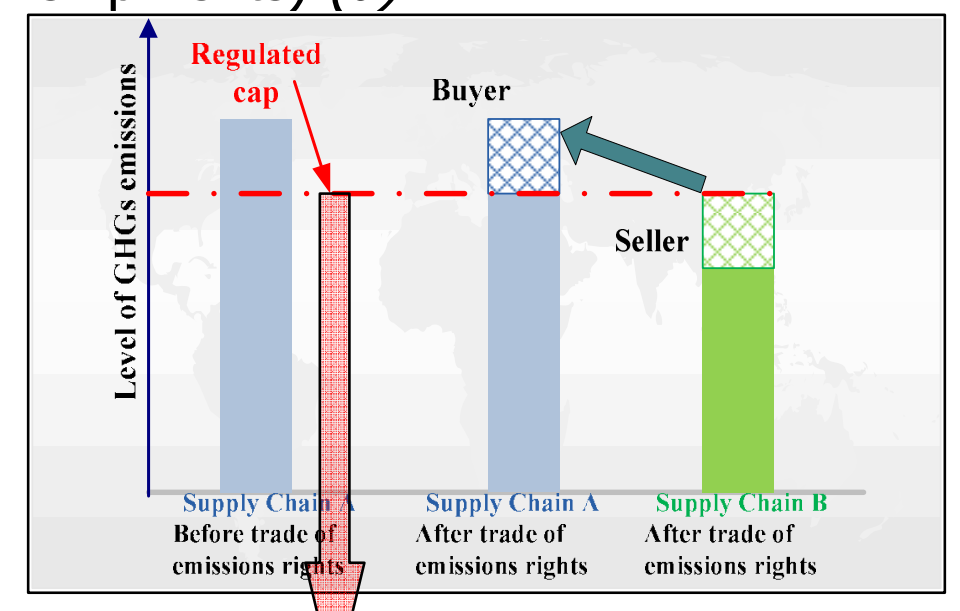

(c) 2008 A. Chaabane, A. Ramuänin, ì. Paquet 


\section{Formulation - Constraints}

- Number of operational sites

$$
\sum_{i \in S_{p} \cup V_{p}} Y_{i p} \leq m_{p}(\forall p \in R \cup M)
$$

- Node capacity

$$
X_{i p}-b_{i p} Y_{i p} \leq 0 \quad\left(\forall p \in R \cup M, \forall i \in S_{p} \cup V_{p}\right)
$$

- Capacity constraints

- Maximum time capacity use for subcontractors

$$
\sum_{p \in M_{i}} X_{i p} t e_{i p}-T_{i} A_{i} \leq 0, \forall i \in S
$$

- Minimum time capacity use for subcontractors

$$
\sum_{p \in M_{i}} X_{i p} t e_{i p}-\rho_{i} T_{i} A_{i} \geq 0, \forall i \in S
$$

- Maximum capacity for suppliers

$$
\sum_{p \in R_{i}} X_{i p}-\left(\rho_{i} \sum_{p \in R_{i}} b_{i p}\right) A_{i} \geq 0(\forall i \in V)
$$

- Conservation of flow

$$
X_{i p}-\sum_{j \in S(\operatorname{Suc}(p)) \cup D} \sum_{k \in K} F_{i j p}^{k} \geq 0 \quad\left(\forall p \in P, \forall i \in V_{p} \cup S_{p}\right)
$$




\section{Formulation - Constraints}

- BOM constraints

$$
\sum_{j \in V_{p} \cup S_{p}} \sum_{k \in K} F_{j i p}^{k}-\sum_{p^{\prime} \in \operatorname{Suc}(p)} g_{p p^{\prime}} X_{i p^{\prime}}=0 \quad(\forall p \in M \cup R, \forall i \in S(\operatorname{Suc}(p)))
$$

- Demand constraints

$$
\sum_{i \in S_{p}} \sum_{k \in K} F_{i d p}^{k}=d_{p d}(\forall p \in C, \forall d \in D)
$$

- Transportation capacity constraints

- Maximum number of transportation modes that can be used

$$
\sum_{k \in K} Z_{i j}^{k} \leq \tau_{i j} \quad(\forall i \in V \cup S, \forall j \in S \cup D)
$$

- Volume capacity

$$
\sum_{p \in R_{i} \cup M_{i}} \delta_{p} F_{i j p}^{k}-\kappa^{k} U_{i j}^{k} \leq 0 \quad(\forall i \in V \cup S, \forall j \in S \cup D, \forall k \in K)
$$

- Weight capacity

$$
\sum_{p \in R_{i} \cup M_{i}} \pi_{p} F_{i j p}^{k}-\psi^{k} U_{i j}^{k} \leq 0 \quad(\forall i \in V \cup S, \forall j \in S \cup D, \forall k \in K)
$$




\section{Formulation - Constraints}

- Logical constraints

- The number of shipments between two nodes is not nil only if the transportation mode is actually used

$$
U_{i j}^{k}-M Z_{i j}^{k} \leq 0 \quad(\forall i \in V \cup S, \forall j \in S \cup D, \forall k \in K)
$$

- A transportation mode is used between two nodes only if the number of shipments is not nil:

$$
Z_{i j}^{k} \leq U_{i j}^{k} \quad(\forall i \in V \cup S, \forall j \in S \cup D, \forall k \in K)
$$

- The number of shipment between two nodes using a transportation mode is nil if there is no flow of products

$$
U_{i j}^{k} \leq \sum_{p \in R_{0} \cup M} F_{i j p}^{k} \quad(\forall i \in V \cup S, \forall j \in S \cup D, \forall k \in K)
$$

- A site is Opperational if it is open for one product at least:

$$
Y_{i p}-A_{i} \leq 0 \quad\left(\forall i \in S \cup V, \forall p \in M_{i} \cup R_{i}\right)
$$




\section{Formulation - Constraints}

- Integer, binary, and non-negativity constraints

- Transport variables and the quantities supplied are non negative

$$
\begin{aligned}
F_{i j p}^{k} \geq 0 & \left(\forall p \in R \cup M, \forall i \in V_{p} \cup S_{p}, \forall j \in S(\operatorname{suc}(p)) \cup D, \forall k \in K\right) \\
X_{i p} \geq 0 & \left(\forall(p, i) \in R \times V_{p} \cup M \times S_{p}\right)
\end{aligned}
$$

- Binary variables:

$$
\begin{aligned}
& Y_{i p} \in\{0,1\}, \forall(p, i) \in R \times V_{p} \cup M \times S_{p} \\
& A_{i} \in\{0,1\}, \forall i \in S \cup V \\
& Z_{i j}^{k} \in\{0,1\} \quad(\forall i \in V \cup S, \forall j \in S \cup D, \forall k \in K)
\end{aligned}
$$

- The number of shipments must be integer:

$$
U_{i j}^{k} \text { integer }\left(\forall p \in P, \forall i \in V_{p} \cup S_{p}, \forall j \in S(\operatorname{Suc}(p)) \cup D, \forall k \in K\right)
$$




\section{Parameters - Data input}

\section{- How to find Emission Factors ?}

- Example: IPCC Emission Factor Database (EFDB)

http://Www.ipcc-nggip.iges.or.jp/EFDB/main.php

\begin{tabular}{|c|c|}
\hline Supply Chain Activity & Data Required \\
\hline Transportation & $\begin{array}{l}\text { - Carbon Emission factor ( } \mathrm{kg} \mathrm{CO}_{2} \text { per gallon) or } \mathbf{C O}_{\mathbf{2}} \text { per } \\
\text { Freight }\left(\mathbf{k g ~} \mathbf{C O}_{\mathbf{2}} \text { per ton-mile) }\right.\end{array}$ \\
\hline Production & $\begin{array}{l}\text { - Carbon Conversion Factor per kg of Product produced } \mathbf{( k g ~} \mathbf{C O}_{2} \\
\text { per } \mathbf{k g})\end{array}$ \\
\hline Plant & $\begin{array}{l}\text { - By plant location, the user enters the Energy Consumption per Space } \\
\text { (e.g. kWh per sq. ft.), the Energy Consumption per Capacity (e.g. kWh } \\
\text { per production hr) and a Carbon Conversion Factor (kg CO2 per kWh). }\end{array}$ \\
\hline Warehouses & $\begin{array}{l}\text { - By warehouse location, the user enters the Energy Consumption (e.g. } \\
\text { kWh per sq ft.), the Carbon Conversion Factor (kg CO2 per kWh) and the } \\
\text { Area to Apply (entire size of warehouse, or average inventory volume) }\end{array}$ \\
\hline
\end{tabular}




\section{Summary of the model (DSS)}

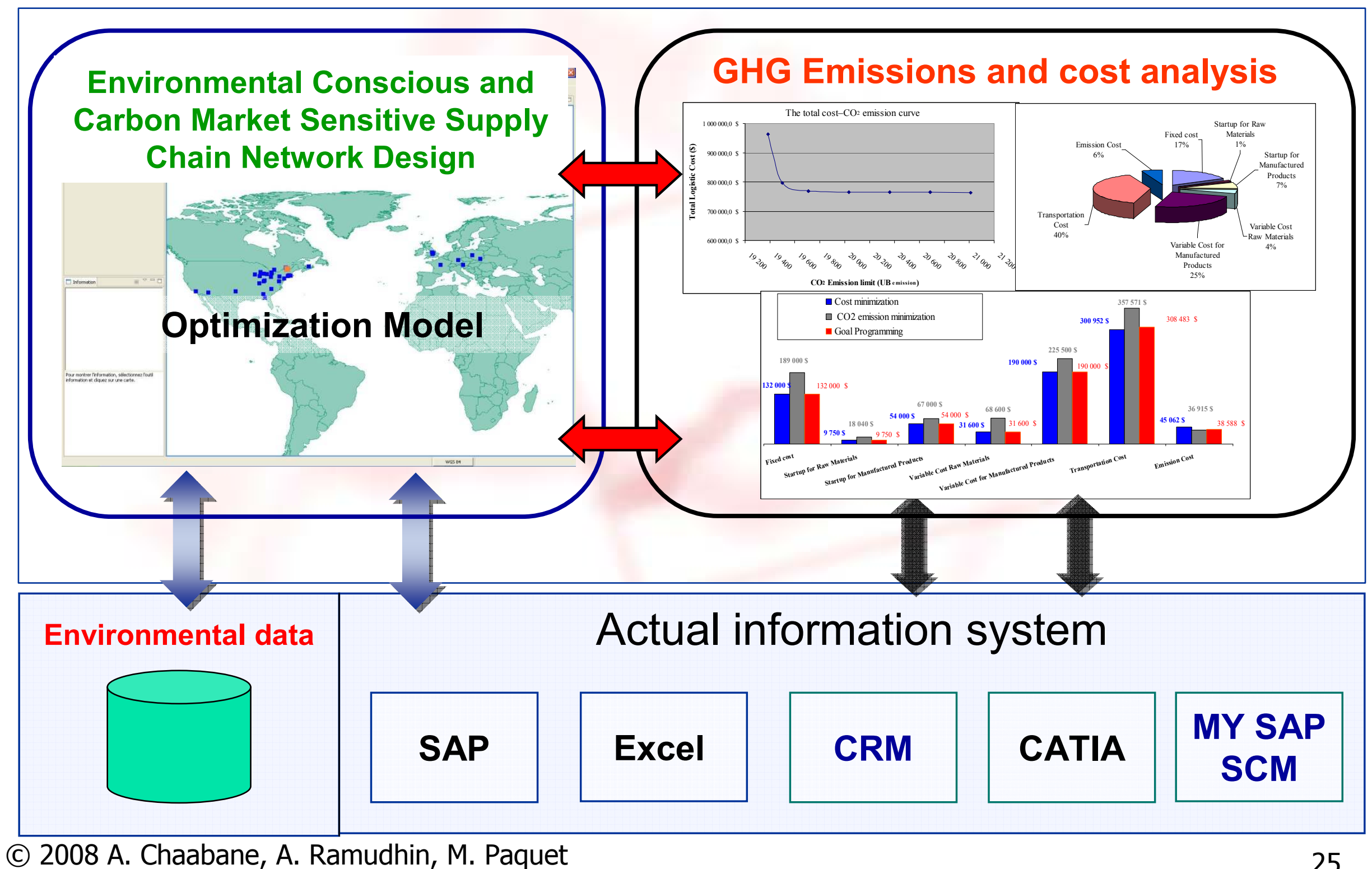

(c) 2008 A. Chaabane, A. Ramudhin, M. Paquet 


\section{Experimentation - Example}

- Environmental supply chain network design example

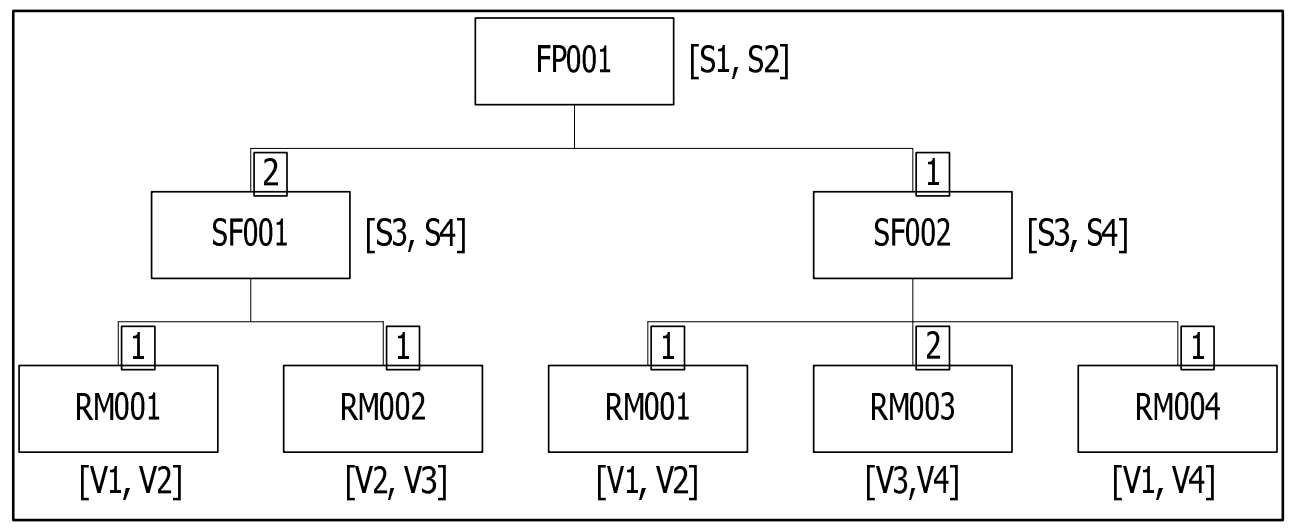

\begin{tabular}{|l|c|c|c|}
\hline $\begin{array}{c}\text { Transportation } \\
\text { mode }\end{array}$ & Type & $\begin{array}{c}\text { Payload } \\
\text { (tons) }\end{array}$ & $\begin{array}{c}\mathrm{CO}_{2} \\
\text { (grams/ton-mile) }\end{array}$ \\
\hline Road & Class 8b & 12.5 & 187 \\
\hline rail & Intermodal rail & 2,093 & 40 \\
\hline air & $\begin{array}{c}\text { Boeing } \\
747-400\end{array}$ & 70 & 1,385 \\
\hline \multicolumn{3}{|c|}{ Freight transportation emission factors } \\
(grams/ton-mile)
\end{tabular}

\begin{tabular}{|c|c|c|c|c|c|c|c|}
\hline & $\begin{array}{c}\text { Number of } \\
\text { variables }\end{array}$ & $\begin{array}{c}\text { Binary } \\
\text { variables }\end{array}$ & $\begin{array}{c}\text { Integer } \\
\text { variables }\end{array}$ & $\begin{array}{c}\text { Continuous } \\
\text { variables }\end{array}$ & $\begin{array}{c}\text { Number of } \\
\text { constraints }\end{array}$ & $\begin{array}{c}\text { Inequality } \\
\text { constraints }\end{array}$ & $\begin{array}{c}\text { Equality } \\
\text { constraints }\end{array}$ \\
\hline $\begin{array}{c}\text { MILP } \\
\text { statistics }\end{array}$ & 207 & 64 & 42 & 101 & 232 & 210 & 22 \\
\hline \multicolumn{7}{|r|}{} \\
MILP model characteristics
\end{tabular}




\section{Experimentation - Results}

- The MILP problem is solved by CPLEX Interactive Optimizer

\begin{tabular}{|l|c|c|}
\hline & $\begin{array}{c}\text { GHG emission limit } \\
\left(U P_{\text {Emission }}\right) \text { (in tons) }\end{array}$ & Total Cost (\$) \\
\hline Base scenario & 21012 & $763364 \$$ \\
\hline Scenario 2 & 20687 & $764421 \$$ \\
\hline Scenario 3 & 20361 & $764421 \$$ \\
\hline Scenario 4 & 20035 & $764421 \$$ \\
\hline Scenario 5 & 19710 & $768802 \$$ \\
\hline Scenario 6 & 19709 & $768802 \$$ \\
\hline Scenario 7 & 19500 & $796032 \$$ \\
\hline Scenario 8 & 19383 & $962626 \$$ \\
\hline
\end{tabular}




\section{Some managerial insights}

- Tradeoffs between cost and $\mathrm{CO}_{2}$ emissions

- Cost analysis

- GHG emissions assessment

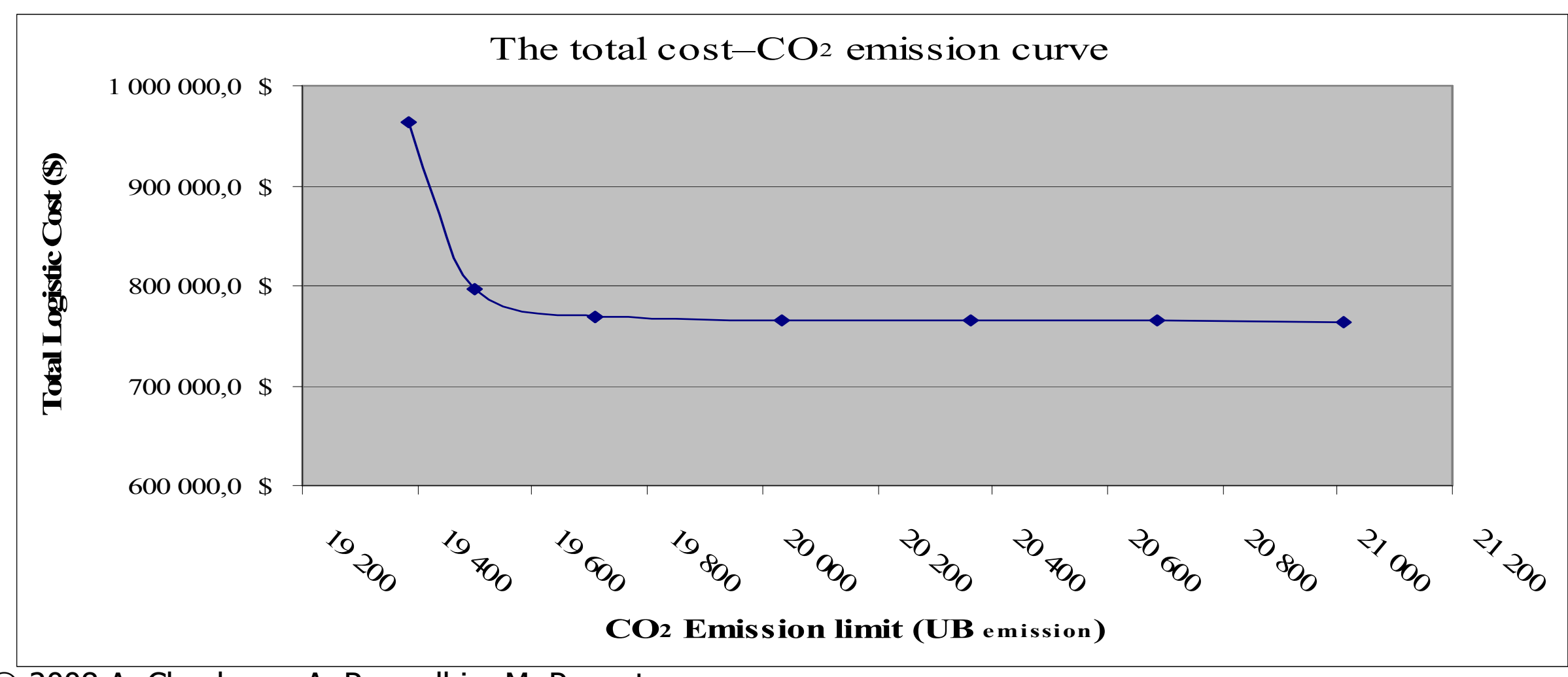

(c) 2008 A. Chaabane, A. Ramudhin, M. Paquet 


\section{Some managerial insights}

Cost minimization versus $\mathrm{CO}_{2}$ emissions minimization

\begin{tabular}{|l|l|l|l|l|}
\hline Base scenario- Cost minimization \\
$\square$ Scenario 8 - CO2 emission minimization \\
Fixed cost \\
Startup for Raw Materials \\
Startup for Manufactured Products \\
Variable Cost Raw Materials \\
Variable Cost for Manufactured Products
\end{tabular}




\section{References}

\section{Thank you}

1. A. Ramudhin, A. Chaabane, M. Kharoune, and M. Paquet. "Carbon Market Sensitive Green Supply Chain Network Design". In Proceeding of the IEEE International conference on Industrial Engineering and Engineering Management (IEEM), Singapore, December 8-11, 2008.

2. A. Chaabane, A. Ramudhin, M. Kharoune, and M. Paquet. "Trade-offs Model for Carbon Market Sensitive Green Supply Chain Network Design". In Proceeding of the Sixth Annual International Symposium On supply Chain Management, Calgary, Alberta, Canada, October 15th - 17th 2008.

3. A. Chaabane, M.A. Benkaddour, A. Ramudhin, and M. Paquet, " An integrated logistics model for environmental conscious supply chain network design", In Proceeding of the Fourteenth Americas Conference on Information Systems, Toronto, Ontario, Canada, August 14th -17th 2008.

\section{Questions?}

